\title{
Equity impacts of price policies to promote healthy behaviours
}

Franco Sassi, Annalisa Belloni, Andrew J Mirelman, Marc Suhrcke, Alastair Thomas, Nisreen Salti, Sukumar Vellakkal, Chonlathan Visaruthvong, Barry M Popkin, Rachel Nugent

Governments can use fiscal policies to regulate the prices and consumption of potentially unhealthy products. However, policies aimed at reducing consumption by increasing prices, for example by taxation, might impose an unfair financial burden on low-income households. We used data from household expenditure surveys to estimate patterns of expenditure on potentially unhealthy products by socioeconomic status, with a primary focus on low-income and middle-income countries. Price policies affect the consumption and expenditure of a larger number of high-income households than low-income households, and any resulting price increases tend to be financed disproportionately by high-income households. As a share of all household consumption, however, price increases are often a larger financial burden for low-income households than for high-income households, most consistently in the case of tobacco, depending on how much consumption decreases in response to increased prices. Large health benefits often accrue to individual low-income consumers because of their strong response to price changes. The potentially larger financial burden on low-income households created by taxation could be mitigated by a pro-poor use of the generated tax revenues.

What are price policies for health promotion, and is their use justified?

The framework for addressing the growing global epidemic of non-communicable diseases (NCDs) was adopted at the 2011 High-level Meeting of the UN General Assembly. ${ }^{1}$ The four leading behavioural risk factors for NCDs in the framework were tobacco use, harmful alcohol consumption, poor diet, and insufficient physical activity. At least three of these risk factors involve the consumption of products purchased in markets that are regulated by national governments to varying degrees. Through regulation and fiscal policies (both taxes and subsidies), governments can affect market prices and create behavioural incentives for health improvement. In the pursuit of the UN's Sustainable Development Goal target to reduce mortality from NCDs, attention is turning to policies that can help achieve this target and the means that are necessary to finance the prevention and control of NCDs. Price policies, particularly increased taxes on tobacco and other potentially unhealthy products, could support both.

Addressing tobacco and harmful alcohol use and improving diet would reduce the prevalence of the most lethal NCDs, such as cardiovascular disease, stroke, cancer, and chronic respiratory diseases, and of injuries and alcohol use disorders. In most countries, these diseases affect $t$ he $\mathrm{p}$ oor $\mathrm{d}$ isproportionately. ${ }^{2}$ Population-level interventions to address those risks have generally been more cost-effective than m edical interventions to treat the diseases. ${ }^{3-6}$

Taxes on tobacco and alcohol are key components of the Framework Convention on Tobacco Control and of WHO's Global Strategy on Tackling Harmful Alcohol Use. ${ }^{7,8}$ Taxes on food and non-alcoholic beverages have been adopted at the national or local level in many countries as part of efforts to improve nutrition and prevent obesity (target populations include socially disadvantaged groups)., ${ }^{910}$ Calls are being made to extend the use of taxes in this area because, for example, increased prices of fast foods and reduced prices of fruits and vegetables are associated with a reduced bodyweight in young and in low-income consumers, respectively. ${ }^{11}$

In addition to using fiscal policies, many countries have tried to regulate the minimum price of alcohol and

\section{Key messages}

- Price policies on potentially unhealthy products alter consumption and expenditure for all consumers, but the effects can differ by socioeconomic status

- Expenditure on potentially unhealthy products increases more for high-income than for low-income households in response to a price increase, but this change in expenditures is often a heavier burden for low-income households than for high-income households because it constitutes a higher share of their overall expenditure; this is particularly true for tobacco products

- Large health benefits are likely to accrue to individual low-income consumers because they generally have the strongest response to price changes

- Whether taxation is regressive depends on how this characteristic is defined; different measures might lead to different policy conclusions (most notably in the case of alcohol), and policy makers must be aware of such differences

- Adverse equity effects of taxes can be mitigated by a propoor use of the tax revenues generated or by adjustments in the distributional effects of the broader tax system
Lancet 2018; 391: 2059-70 Published Online April 4, 2018 http://dx.doi.org/10.1016/ S0140-6736(18)30531-2

See Comment pages 1972, 1973, and 1975

See Series pages 2029, 2036 2047, and 2071

This is the fourth in a Series of five papers about non-communicable diseases and economics

Centre for Health Economics and Policy Innovation, Imperial College Business School, London, UK (Prof F Sassi PhD), Public Health England, London, UK (A Belloni MSc); University of York, York, UK (A) Mirelman PhD, Prof M Suhrcke PhD); Luxembourg Institute of Socio-Economic Research, Esch-sur-Alzette, Luxembourg (Prof M Suhrcke); Organisation for Economic Co-operation and Development, Paris, France (A Thomas MSc); American University of Beirut, Beirut, Lebanon (N Salti PhD); Birla Institute of Technology and Science, Pilani, Goa, India (S Vellakkal PhD); Ministry of Finance, Bangkok, Thailand (C Visaruthvong Phd); University of North Carolina at Chapel Hill, Chapel Hill, NC, USA (B M Popkin PhD); and Research Triangle Institute International, Seattle, WA, USA (R Nugent PhD)

Correspondence to:

Prof Franco Sassi, Centre for Health Economics and Policy Innovation, Imperial College Business School, London SW7 2AZ, UK f.sassi@imperial.ac.uk 
tobacco products and use price promotions to increase sales. A $10 \%$ increase in the minimum price of alcohol in Canada has been estimated to reduce acute alcoholattributable hospital admissions and chronic alcoholattributable admissions 2 years later, both by about $9 \% .{ }^{12}$

Taxes are also an important source of revenue. Tobacco taxes were described in the Addis Ababa Financing for Development outcome document ${ }^{13}$ as offering "a revenue stream for financing for development in many countries". Data from the Organisation for Economic Co-operation and Development (OECD) show that in 2015, tobacco and alcohol excise taxes contributed to about $1 \cdot 2-1 \cdot 7 \%$ of total tax revenues in Argentina, Denmark, and Belgium, to about $3.3 \%$ of total tax revenues in the UK and Hungary, and to more than $\mathbf{9 . 5 \%}$ of total tax revenues in Venezuela. In Denmark, tax on saturated fat content in foods accounted for $0.14 \%$ of total tax revenues between 2011 and 2012. WHO has estimated that increasing cigarette taxes by $50 \%$ in low-income countries like DR Congo, Laos, Vietnam, or Madagascar would generate additional revenues equivalent to more than $25 \%$ of current government expenditure on health. Increasing taxes on alcohol to $40 \%$ of beverage retail prices would have at least as large effects. ${ }^{14}$

In theory, price policies interfere with the functioning of markets and with individual choice, but they can be justified when markets do not function efficiently. This is typically the case, for example, when consumers do not bear the full cost of their choices because the market prices of the products they consume do not reflect harms to others (eg, from second-hand smoking, alcohol-related traffic accidents, or violence) or the extra health-care costs borne collectively. ${ }^{15-17}$ The consumption of such products tends to be higher than socially desirable. The addictive properties of some products and the influence of commercial advertising increase consumption further.

Evidence that consumers respond to price incentives justifies the expectation that price policies will generate beneficial health effects. However, the equity effects of price policies have been a concern for many governments. Expenditures due to increased prices are widely perceived to weigh most heavily on the incomes of people of low socioeconomic status, although the same people might also benefit more from price policies than others in health terms. ${ }^{18}$

We have assessed the existing evidence and household survey data on the equity effects of price policies on potentially unhealthy products. In this Taskforce paper, we discuss the equity effects in terms of both their financial and health consequences on individuals and households in countries at different levels of income. We bring together different sets of findings to help policy makers decide whether concerns about the equity effects of price policies are a legitimate barrier to the use of these policies in the pursuit of health goals. Many of the examples presented here are related to taxes because they are most commonly used, but our analyses and conclusions are applicable to a broad range of price policies, such as subsidies or price regulation.

\section{Socioeconomic patterns of potentially unhealthy consumption}

We start by considering how consumption differs between groups with different socioeconomic status to gauge the likely effects of price policies. We assessed patterns of consumption by socioeconomic status for four aggregates of products: tobacco products (hereinafter tobacco); alcoholic beverages (alcohol); non-alcoholic beverages, excluding water (soft drinks); and snacks and confectionery products (snacks). These aggregates differ slightly between countries in terms of the products they contain. A complete set of definitions is provided in the appendix. Socioeconomic status is a function of income or total (expenditure-based) household consumption, depending on data availability (hereinafter income, for ease of reference). Our findings are primarily presented as top-to-bottom quintile ratios (ie, as ratios between the average value of the relevant outcome in the top quintile and the average value in the bottom quintile). Results for individual quintiles are fully reported in the appendix, and they show that in a few countries, the relevant outcomes are not uniformly increasing or decreasing across groups with different socioeconomic status, which should be considered when interpreting top-to-bottom quintile ratios.

The countries included in the analysis were selected on the basis of the availability of good quality data from relatively recent expenditure surveys (undertaken in or since 2000). These countries provide wide geographical coverage in Latin America (Chile, Guatemala, Panama, Nicaragua), central-eastern Europe (Albania, Poland Turkey), central Asia (Tajikistan); sub-Saharan Africa (Tanzania), west Africa (Niger, Nigeria), and south and east Asia (India, Timor-Leste). These countries cover a wide range of national income levels, from high income (Chile and Poland) to low income (Niger, Tanzania), but exclude OECD countries with the highest income.

\section{Prevalence of consumption and average expenditure on potentially unhealthy products in different socioeconomic groups}

Top-to-bottom quintile ratios of consumption prevalence for each of the four aggregates of products are shown in figure 1. Consumption prevalence includes all households with a positive (ie, greater than zero) expenditure during the period covered by each survey, using data from four national surveys (Chile, India, Poland, and Turkey) and from a subset of the Living Standards Measurement Surveys (an international collection of harmonised national household expenditure surveys supported by the World Bank). A parallel set of bars in the same figure shows top-to-bottom quintile ratios of expenditures for consumers of the four aggregates of products only 

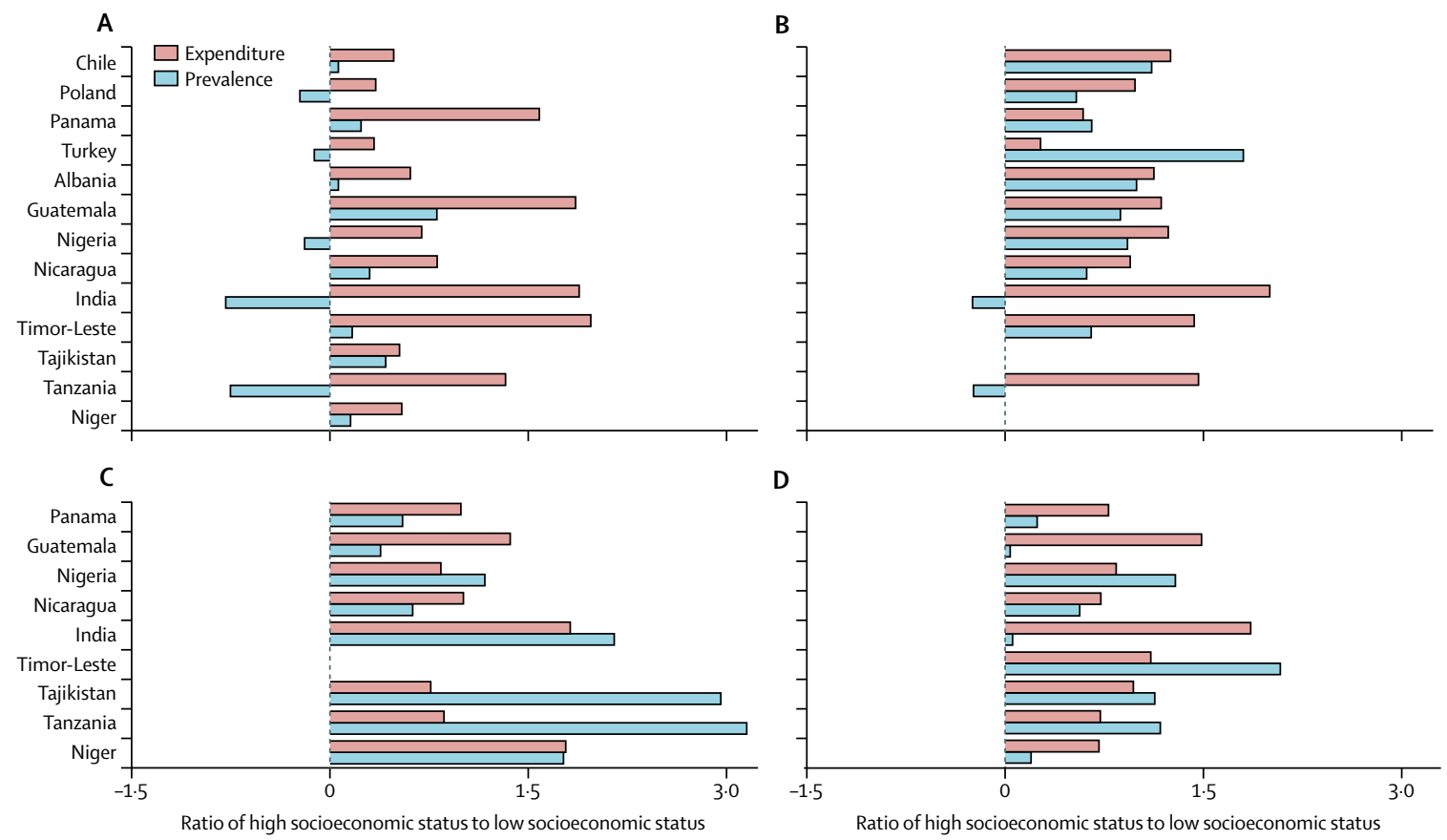

Figure 1: Socioeconomic disparities in the prevalence of consumption and household expenditure on four product aggregates

Ratio of household expenditure on or prevalence of consumption of (A) tobacco, (B) alcohol, (C) soft drinks, and (D) snacks in the group with high socioeconomic status (top wealth quintile) over expenditure or prevalence in the group with low socioeconomic status (bottom quintile). Expenditure ratios were calculated in consumers only. Ratios were calculated after logarithmic transformation of prevalence and expenditure values. Ratios above zero indicate larger prevalence or expenditure in the top wealth quintile; negative ratios indicate larger prevalence or expenditure in the bottom quintile.

(ie, excluding households that do not consume those products) in the same surveys. Differences in expenditure levels between socioeconomic groups might reflect different levels of consumption and different price levels paid by different groups of consumers (eg, because they consume a more or less expensive mix of products within the relevant aggregate). The latter differences are likely to be small in relatively homogeneous product aggregates (eg, soft drinks) but large in heterogeneous aggregates (eg, alcohol). For example, the high-income group is likely to consume more expensive types of alcohol than the lowincome group. A large expenditure resulting from the consumption of expensive products will lead to larger tax payments than from the consumption of cheap products only if taxes are proportional to prices (ie, ad valorem).

\section{Tobacco}

There is no clear or consistent pattern of prevalence of tobacco use by socioeconomic status in the selected countries (figure $1 \mathrm{~A}$ ). $\mathrm{T}$ he $\mathrm{c}$ learest g radient of a $11 \mathrm{t}$ he countries examined is seen in Guatemala, with people in the top-consumption quintile 2.4 times more likely to use tobacco products than people in the bottom quintile. Individual behaviours cannot be gauged from household expenditure data, but other data sources can shed light on patterns of tobacco use for men and women. For example, data from the Demographic and Health Surveys, which rely on individual self-reports, show a clear inverse relation in several countries between socioeconomic status and tobacco use in men but the opposite pattern in women (even in Albania, where no clear gradient is seen in household-based prevalence data). ${ }^{19}$

By contrast, top-to-bottom quintile ratios of tobacco expenditure (figure 1A) show consistent gradients across countries, with substantially larger expenditures by wealthy households than by poor households. In absolute terms, the largest burden will be borne by the wealthiest households because of their large expenditures on tobacco products (more than six times larger than that of lowincome households in countries like India, Timor-Leste, and Guatemala).

\section{Alcohol}

Socioeconomic patterns are clear for alcohol use (figure 1B). High socioeconomic status is associated with a high prevalence of alcohol use in most countries in our analyses (the exceptions are India and Tanzania, which display a gradient in the opposite direction, and Nicaragua, which shows no consistent gradient). Data from household expenditure surveys do not necessarily reflect the patterns of drinking that put people most at risk, such as binge drinking and regular heavy drinking. Other data sources indicate that harmful drinking is most common in men of low socioeconomic status and in women of high socioeconomic status, at least in many OECD countries. ${ }^{20}$ The gradient in average expenditure 
on alcohol is substantially steeper than the gradient in consumption prevalence, with the wealthiest households spending larger amounts than households at the bottom of the socioeconomic scale (in Timor Leste and Tanzania, household expenditure on alcohol in the wealthiest households is more than four times that of the poorest households; in India, household expenditure on alcohol in the wealthiest households is more than seven times that of the poorest households). Policies aimed at increasing the prices of alcoholic beverages will therefore affect fewer poor households than rich households, and the economic burden, in absolute terms, will fall disproportionately on those people who are financially better off, although heterogeneity in patterns of consumption means that some poor households might still bear a large financial burden.

\section{Soft drinks and snacks}

Although data for soft drink consumption are available for fewer countries than for tobacco and alcohol consumption, the patterns for soft drink consumption are similar to those for alcohol (figure 1C). Both the prevalence of soft drink use and expenditures on these beverages are highest in the wealthiest households. The gradients in household expenditure are somewhat less steep than those observed for alcohol, but expenditure in India and Niger differs up to three-fold between socioeconomic groups. However the soft drinks aggregate is broad and includes different types of beverages (eg, with added sugar, with naturally occurring sugars, and with artificial sweeteners), potentially with different patterns of use by socioeconomic group, and some of these beverages might not be the targets of price policies. Patterns are less clear for snacks (figure 1D), but expenditure gradients are consistent with those seen for soft drinks, with largest expenditures by the wealthiest households. Again, the largest difference in expenditure between socioeconomic groups is in India (more than three-fold).

Patterns by socioeconomic group vary between countries, but without a clear correlation with income or geography (figure 1). Other country characteristics, presumably those associated with national culture and traditions, seem to have a more important role.

\section{Distribution of the health outcomes of price policies}

The data examined so far show the shares of households whose consumption would be affected by price policies. However, the effects of price policies on health are determined, above all, by the degree to which consumers respond to price changes (referred to, in economic terms, as price elasticity of demand) and by the substitutions that consumers might make in response to changes in the prices of the products they purchase. Evidence of consumer responses to price changes is not available in all countries or for all products. In this section, we summarise findings from relevant studies.
For most of the products targeted by taxation or price regulation, the proportionate change in consumption to be expected is generally less than the proportionate change in price caused by the policy (so-called inelastic demand). For some products (eg, sugar-sweetened beverage ${ }^{11}$ ) and some population groups (eg, young smokers), the change in consumption is proportionately larger than the change in price. An inelastic demand that is partly due to addiction (at least in the case of tobacco and alcohol products) tends to be associated with limited substitutions by consumers, a high likelihood of the tax being passed on to consumers (as opposed to being absorbed by suppliers), and large revenues for governments. An inelastic demand also means that a price intervention has to be relatively large to elicit a response that might lead to meaningful health gains.

Most importantly, the size of consumer responses to price changes is a strong indicator of potential health gains, and different responses by people in different socioeconomic groups mean that a price policy could affect the distribution of health gains across socioeconomic groups. For example, a large response in groups with low socioeconomic status, which is often due to relatively tight budget constraints, is also an indicator of greater health improvements in the poor. Yet other factors come into play as well because health outcomes will also depend on initial consumption levels and the degrees of risk associated with them.

\section{Tobacco}

The demand for tobacco products in low-income and middle-income countries (LMICs) is at least as responsive, and often more responsive, to price as it is in high-income countries, ${ }^{21}$ with some study findings suggesting the demand in LMICs could be twice as responsive as in highincome countries. ${ }^{22}$

Evidence suggests that young and low-income consumers within countries have the strongest response to price changes, although evidence of a socioeconomic gradient in price elasticity is less consistent in LMICs. ${ }^{21,22}$ In China, the response is five times larger in the bottom income quintile than in the top quintile, and twice as large in people younger than 24 years than in people aged 65 years or older. ${ }^{23}$ In Bangladesh, on the basis of a three-level income classification, the response to price changes is at least two times stronger in low-income cigarette smokers than in high-income smokers. ${ }^{24}$ In both countries, the socioeconomic gradient in consumer responses to price changes is largely due to different changes in smoking participation, with virtually no gradient in demand reductions by those who continue to smoke. ${ }^{24,25}$

\section{Alcohol}

Consistent evidence suggests that increases in the prices of alcoholic beverages reduce alcohol consumption. ${ }^{26-29}$ 
The response of alcohol drinkers to price changes are similar in countries at all levels of income. ${ }^{30}$ Despite a widespread belief (and at least some evidence ${ }^{31}$ ) that the response to price changes is stronger in low-income drinkers than in high-income drinkers, empirical assessments of the size of a possible socioeconomic gradient in the response and of how the gradient might vary between countries at different 1 evels o f i ncome a nd development remain limited. ${ }^{32}$ The response to the possible introduction of a minimum price for alcohol in the UK was estimated to be 7.6 times larger in drinkers in the lowest-income quintile than in drinkers in the highest-income quintile. ${ }^{33}$

\section{Food and non-alcoholic beverages}

Data on the effect of relevant food prices on consumption or sales have been synthesised in a large number of systematic or structured reviews. ${ }^{12,3440}$ A few comprehensive reviews include data from LMICs. Green and colleagues $^{39}$ used evidence from 136 studies and 3495 estimates to characterise consumer consumption responses to changed prices (so-called own-price elasticity). Cornelsen and colleagues ${ }^{40}$ used data from 78 studies and 4162 estimates to examine the much less frequently assessed substitutions that might occur as a result of price changes (so-called cross-price elasticities). Nakhimovsky and colleagues ${ }^{41}$ focused on own-price elasticity of sugar-sweetened beverages in middle-income countries.

Increases in the prices of food and non-alcoholic beverages elicit the greatest changes in consumption in low-income countries, whereas the smallest changes are seen in high-income countries. Within countries, price elasticities for different food a nd b everage p roducts a re higher in lowest-income groups than in highest-income groups. Yet the differences $\mathrm{i} \mathrm{n} \mathrm{p}$ rice e lasticities a re relatively small, with a response by lowest-income consumers that is $1 \cdot 14-1 \cdot 21$ times larger than that of highest-income consumers. The data on within-country differences, h owever, i s p redominantly from s tudies of high-income countries (limited to 21 studies at present). ${ }^{39}$ Results are similar for sugar-sweetened beverages, with greatest or similar benefits a ccruing t o p eople of 1 ow socioeconomic status in middle-income ${ }^{41}$ and highincome countries. ${ }^{42}$ Tax on sugar-sweetened beverages has been introduced in Mexico in 2014, and the response oflow-income consumers to this tax is described in panel 1.

\section{Additional factors affecting the health effects of price policies}

The evidence presented in this section points to a larger reduction in consumption in people of low socioeconomic status than in people of high socioeconomic status, which will probably result in largest health gains for the former group if benefits are not offset by unhealthy substitutions. This partly depends on the respective initial levels of consumption and risk. This social gradient is especially steep for tobacco in high-income countries and is less consistent in LMICs. Similar gradients also exist in consumer responses to changes in prices of alcohol (although empirical evidence of these responses is limited), food, and non-alcoholic beverages, but the gradients are substantially smaller for food and non-alcoholic beverages than for alcohol. The size and type of substitutions that consumers will make is to a large extent the result of how price policies are designed and how the tax base is defined (ie, what products are targeted), and evidence that substitution patterns differ between socioeconomic groups is limited at present.

Although health gains for individual consumers can be expected to be larger in groups with low socioeconomic status than in groups with high socioeconomic status, aggregate health gains for whole groups might not have the same distribution. This is because the prevalence of consumption differs between socioeconomic groups, especially in the case of alcohol. However, additional factors might contribute to determining aggregate health outcomes in different socioeconomic groups; examples include differences in patterns of consumption and the degrees of risk associated with the consumption, access to care, and concurrent exposures (eg, environmental factors). The long-term outcomes of price policies are therefore best estimated through mathematical models. A recent example is the Chronic Disease Prevention model developed by OECD and WHO, in which a package of fiscal policies including taxation of high-fat foods and subsidies on fruit and vegetables was estimated to lead to larger aggregate health gains in people of low socioeconomic status than in people of high socioeconomic status. ${ }^{5,47}$

\section{Financial effects of price policies in different socioeconomic groups}

Governments' concerns about the potentially regressive financial effects of price policies for health promotion have been one of the main barriers to a wider use of such policies. However, the meaning of regressive is not always clearly or consistently defined in the public debate beyond its generic association with a large financial burden placed on low-income individuals or households. In the case of taxes, for example, the most common measure of financial burden in a given socioeconomic group is the average ratio between taxes paid and ability to pay (commonly proxied by income or disposable income, but also by total household expenditure) across all households in that group. This measure does not take into account the positive financial effects of taxes on health. Also, this tax burden measure is heavily influenced by the proportion of households that consume the taxed product in each group, such that the tax burden will be lowest in groups in which fewest households consume the product. Reducing the prevalence of consumption is a goal of price policies for health promotion, so it is important to account for prevalence reduction as a factor that helps to contain 
Panel 1: Mexico's sugar-sweetened beverage tax: the largest response is by low-income consumers

Mexico's obesity and type 2 diabetes problems are among the most serious in large countries. The burden is particularly large on lower-income Mexicans who are much less likely to be diagnosed and successfully treated for their type 2 diabetes. On the basis of these health concerns, the Mexican Government implemented an excise tax of 1 peso per $L$ sugar-sweetened beverage (approximately $10 \%$ of the price), in Jan 1, 2014, with an inflation adjustment once inflation was at $10 \%$ or more.

In the period leading up to the institution of this tax, there was a large battle between the beverage sector and a coalition of Mexican consumer federations advocating the tax and funded mainly by grants from Bloomberg Philanthropies. Public opinion emerged as strongly in favour of taxing sugar-sweetened beverages, and the President backed the proposal.

Researchers estimated changes in household purchases of beverages in 2014 compared with 2012 and 2013. Longitudinal fixed-effects models that examined the difference in trends before and after the tax (difference in differences model) were to account for a pre-existing decrease in purchases of sugar-sweetened beverages over the 2-year period before the tax, using household socioeconomic status and composition and contextual controls for changing economic conditions (city-level unemployment and salary levels).

Beverage purchases collected biweekly from a panel of urban households between 2012 and 2015 provided the panel data. Results of price research showed the full amount of the tax (or more) was passed through to consumers for smaller bottle sizes but not always for larger ones. ${ }^{43}$ Pass-through was also lower in poor rural areas than in all urban areas.

In 2014, purchases of taxed beverages decreased by an overall average of $6 \%$, reaching a $12 \%$ reduction by December, $2014 .{ }^{44}$ This translates to an average of $4 \cdot 2 \mathrm{~L}$ less sugar-sweetened beverage purchased per person in 2014. The tax had the

the burden of taxation (or price policies more generally) in a given socioeconomic group. The main limitation of a burden measure encompassing all households is that it does not reflect the real burden borne by households whose members consume the product. To determine this, households that do not consume the product in question should be excluded from group averages, which we did in the calculation of a second measure of the financial burden of price policies (referred to as consumers only), shown alongside whole-group averages. Again, we relied on household expenditure survey data from the countries previously examined.

A further important distinction is between the distribution of the burden of a price policy and the distribution of the burden caused by a change in an existing policy. Tobacco and alcohol taxes, for example, are almost universal, and the relevant policy question is not whether these products should be taxed but whether existing taxes should be increased. A tax can be greatest effect on households with low socioeconomic status, with a $9 \%$ average decrease in purchases of sugary drinks in 2014 and a 17\% decrease by December, 2014. The top socioeconomic tertile did not reduce purchases of sugar-sweetened beverages substantially. Furthermore, the purchase of untaxed beverages increased by $4 \%$ overall, which was primarily driven by an increase in bottled water purchases. This suggests that consumers are substituting healthier beverages in place of sugar-sweetened beverages, which translates to about $12.8 \mathrm{~L}$ additional water purchased per capita. Concurrent with the tax, beverage companies used a vast array of promotions (eg, free food with purchases of sugar-sweetened beverages), but these appear to have had little effect.

In longitudinal analyses of both first and second year comparisons with the 2012-13 baseline, purchases decreased by an additional $4 \%$ beyond the decrease in purchases in the first year, with the greatest change in the poorest households (overall $-9.0 \%$ in 2014 and $-14.3 \%$ in 2015). ${ }^{45}$ This result was replicated in an analysis of national sales per capita data. ${ }^{46}$

The 1-year tax effect is moderate but important, particularly for the population with the lowest socioeconomic status. This group paid much less tax because it purchased substantially fewer sugar-sweetened beverages. This group was most likely to increase water purchases. Part of the revenues is being used to provide potable water to public schools mainly for children in lower-income and middle-income populations. It will take a number of years of this tax before the reduction in sugar consumption will create visible health improvements, but this econometric analysis of directly measured transactions of all food and beverage purchases shows promise that the tax will differentially improve the diet and, ultimately, the health of Mexicans of low socioeconomic status.

regressive, yet an increase in the same tax might attenuate its regressive effect if the response by low-income households were sufficiently larger than that of high-income households. A weak response (typical of high-income groups) is associated with a large increase in expenditure on a taxed product (and therefore a large increase in tax paid). This is illustrated using the example of a tobacco tax hike in Lebanon (panel 2). These are average effects, summarising individual situations that range from a reduced tax burden for those who stop consuming the taxed product to an increased burden for those who are least responsive to price changes.

As an extension of research by the OECD on the effects of consumption taxes in different socioeconomic groups ${ }^{60}$ we estimated the distribution of the burden of excise taxes on alcohol and tobacco in three OECD countries (Chile, Poland, and Turkey), selected as the countries within the OECD with the lowest gross-domestic product per capita, for which data were available; Poland and Turkey are also 
Panel 2: Simulating the distributional effects of a hypothetical increase in the prices of tobacco through taxation in Lebanon

Lebanon has the health and tobacco consumption profile typical of many middle-income countries: non-communicable disease is the number one cause of death, with ischaemic heart disease alone accounting for more than $30 \%$ of deaths. ${ }^{48}$ The smoking prevalence, at $43 \%$ for men and $28 \%$ for women is one of the highest in the Middle East. ${ }^{49}$ Smoking intensity in Lebanon is also three times the world average and increased by 475\% between 1990 and 2012. ${ }^{50}$ Unlike many high-income countries, where taxes are almost two-thirds of tobacco retail price, the share of taxes in price is closer to $47 \%$ in Lebanon. Estimated demand elasticities for different tobacco products imply that increasing taxes has the potential to generate substantial additional tax revenue. ${ }^{51}$

We simulated the distributional consequences of a potential increase in tobacco taxes (table). We used an Almost Ideal Demand System ${ }^{55}$ to estimate the elasticities of demand for imported cigarettes by quintile; as in the study by Salti and colleagues, ${ }^{58}$ we simulated the financial consequences of increased tobacco prices for each quintile by running an extended cost-effectiveness analysis. ${ }^{59}$ The outcomes of this analysis is based on the consumption of imported cigarettes because their share of total spending on all tobacco products in Lebanon is close to $90 \%$. Before a tax increase, the unconditional tax burden was only progressive, moving from the poorest to the second quintile, regressive thereafter. The conditional tax burden showed progressivity from the poorest to the middle quintile. After a tax increase, higher cigarette prices led some smokers to quit and others to reduce their smoking intensity. The largest relative (and absolute) reductions in consumption

part of a group of 23 countries with high burdens of NCDs (figure 2). ${ }^{61}$ The tax burden in these countries is measured as a ratio between tax expenditure and total household expenditure. However, the numerator of this measure is not available for other LMICs examined in this Taskforce paper. For the latter, we present distributions of the proportion of household expenditure on tobacco, alcohol, soft drinks, and snacks, which is a proxy of tax burden.

\section{Tobacco}

In Chile, Poland, and Turkey, the two measures of tax burden (all households and consumers only) lead to similar conclusions about the distribution of the burden of tobacco taxation because differences in the prevalence of consumption between socioeconomic groups are very small (prevalence increases slightly with income in Chile and decreases slightly with income in Poland and Turkey). In all three countries, the burden from tobacco taxes is roughly three times larger in the bottom-income quintile than in the top-income quintile.

\section{Alcohol}

The distribution of the tax burden between socioeconomic groups is very different for alcohol (figure 2B) from quitting were in the poorest quintile and the smallest reductions in the richest quintile. We report only the quitting rates, but the drop in intensity follows the same pattern across quintiles. These findings indicate that more of the health gains from lower consumption accrue to poorer quintiles.

The additional tax revenue was financed primarily by the richer quintiles (31\%), with only $7 \%$ of the additional taxes collected from the poorest quintile. However, as a fraction of total household expenditures, the additional taxes paid were a larger share of total spending for the second and middle quintiles.

Similarly, the additional expenditures on tobacco products resulting from the increase in taxes were financed primarily by the richer quintiles (34\%). However, these additional financial outlays represented a larger share of household expenditures for the second and middle quintiles, and a smaller share for the poorest and the top two quintiles. When we restricted our analysis to smokers, the financial burden of higher spending on tobacco increased as we moved from the poorest to the middle quintile, and decreased slightly for the fourth and richest quintiles. However, smokers in the poorest quintile bore a considerably smaller burden than patients in the top quintiles.

In the context of a middle-income country like Lebanon with a heavy burden of tobacco-related disease, there are substantial health and financial benefits to increasing taxes on tobacco, which do not systematically come at the cost of more disadvantaged socioeconomic groups. Rather, such fiscal measures can curb risky behaviour and generate tax revenue while making the overall tobacco tax structure relatively more progressive.

because of the substantially larger prevalence of alcohol use in groups with high socioeconomic status than in groups with low socioeconomic status. The burden of alcohol excise taxes averaged across all households in each quintile is progressive in all three countries, with households in the top-income quintile bearing a burden that is between 1.6 (Chile) and 2.8 (Turkey) times larger than the burden for households in the bottom-income quintile. However, the tax burden borne by households that do consume alcohol is very slightly regressive in Chile and Poland and more steeply regressive in Turkey, where the burden is 2.4 times larger in the bottomincome quintile than in the top-income quintile. This means that the burden of alcohol taxes is borne disproportionately by higher-income groups, but the financial burden borne by individual low-income households consuming alcohol is proportionately larger than the financial burden borne by high-income households consuming alcohol. This conclusion is consistent with the data from a UK study, ${ }^{62}$ which showed a progressive pattern for a $5 \%$ increase in alcohol prices, in terms of average effects across all households, and a regressive pattern when the denominator included only households consuming alcohol. 


\begin{tabular}{|c|c|c|c|c|c|c|}
\hline & Q1 (poorest) & Q2 & Q3 & Q4 & Q5 (richest) & Total \\
\hline \multicolumn{7}{|l|}{ Before the tax increase } \\
\hline Total spending on imported cigarettes (in US\$ millions) & 58 & 121 & 159 & 184 & 216 & 738 \\
\hline $\begin{array}{l}\text { Taxes paid as percentage of household spending } \\
\text { (unconditional) }\end{array}$ & $1.9 \%$ & $2 \cdot 5 \%$ & $2 \cdot 4 \%$ & $2 \cdot 0 \%$ & $1.7 \%$ & $2.0 \%$ \\
\hline Number of smokers (in thousands) & 217 & 221 & 213 & 194 & 176 & 1210 \\
\hline $\begin{array}{l}\text { Taxes paid as percentage of household spending for } \\
\text { smokers (conditional) }\end{array}$ & $6.9 \%$ & $8.8 \%$ & $8.8 \%$ & $8.0 \%$ & $7 \cdot 6 \%$ & $8.1 \%$ \\
\hline \multicolumn{7}{|l|}{ After the tax increase } \\
\hline $\begin{array}{l}\text { Number of quitters as a result of tax increase } \\
\text { (in thousands) }\end{array}$ & $20 \cdot 2$ & $17 \cdot 4$ & $16 \cdot 1$ & $13 \cdot 6$ & $11 \cdot 3$ & $78 \cdot 5$ \\
\hline Percentage of smokers who quit & $9.0 \%$ & $8.0 \%$ & $7 \cdot 5 \%$ & $7 \cdot 0 \%$ & $6 \cdot 4 \%$ & $7 \cdot 7 \%$ \\
\hline Increased tax revenue (in US\$ millions) & 45 & 9 & 129 & 150 & 179 & 600 \\
\hline Percentage of increased tax revenue borne by quintile & $7 \cdot 0 \%$ & $16 \cdot 0 \%$ & $21 \cdot 0 \%$ & $25 \cdot 0 \%$ & $31 \cdot 0 \%$ & $100 \cdot 0 \%$ \\
\hline $\begin{array}{l}\text { Increased tax revenue as percentage of pretax } \\
\text { increase household expenditures }\end{array}$ & $1.6 \%$ & $2 \cdot 2 \%$ & $2 \cdot 1 \%$ & $1.8 \%$ & $1 \cdot 6 \%$ & $1.8 \%$ \\
\hline $\begin{array}{l}\text { Increased tax revenue as percentage of pretax increase } \\
\text { household expenditures for smokers (conditional) }\end{array}$ & $6 \cdot 4 \%$ & $8 \cdot 4 \%$ & $8 \cdot 6 \%$ & $8.0 \%$ & $7 \cdot 7 \%$ & $7 \cdot 7 \%$ \\
\hline $\begin{array}{l}\text { Increased tobacco expenditures by households } \\
\text { (in US\$ millions) }\end{array}$ & 14 & 36 & 49 & 59 & 74 & 232 \\
\hline $\begin{array}{l}\text { Percentage of total increase in expenditures on } \\
\text { tobacco by quintile }\end{array}$ & $24 \cdot 0 \%$ & $30 \cdot 0 \%$ & $31.0 \%$ & $32 \cdot 0 \%$ & $34.0 \%$ & $31.0 \%$ \\
\hline $\begin{array}{l}\text { Additional tobacco expenditures by households as } \\
\text { percentage of household expenditures (unconditional) }\end{array}$ & $1.1 \%$ & $1.7 \%$ & $1.7 \%$ & $1 \cdot 5 \%$ & $1.3 \%$ & $1.5 \%$ \\
\hline $\begin{array}{l}\text { Additional tobacco expenditures by households as } \\
\text { percentage of household expenditures for smokers } \\
\text { (conditional) }\end{array}$ & $4.7 \%$ & $6.8 \%$ & $6.9 \%$ & $6.6 \%$ & $6 \cdot 5 \%$ & $6 \cdot 3 \%$ \\
\hline
\end{tabular}

Spending data are from the nationally representative multipurpose survey of household living conditions in Lebanon, collected in $2004 . .^{52}$ Import data are from the National Customs Authority of Lebanon, ${ }^{53}$ and tax revenue calculations are based on Ministry of Finance documentation on the tax structure of cigarettes. ${ }^{54}$ Simulations are based on estimated elasticities of demand for imported cigarettes by quintile (authors' calculation by applying an Almost Ideal Demand System ${ }^{55}$ model to household expenditure data from the same survey). Half of the elasticity is assumed to be from participation and the other half from intensity. ${ }^{56}$ Prevalence data is from the Institute for Health Metrics and Evaluation, and demographic data are from the Ministry of Public Health of Lebanon. ${ }^{57}$ Conditional figures were calculated assuming that smokers are uniformly distributed across household expenditures within each quintile.

Table: The simulated consequences of a $50 \%$ increase in the price of cigarettes by taxes, tobacco finances, and smoking behaviour in Lebanon

The share of total household expenditure spent on the four product categories in different socioeconomic groups is shown in figure 3 . Tobacco products account for a larger proportion of expenditure in low-income households than in high-income households (figure 3A), with few exceptions (Tajikistan, Timor-Leste, Panama). Average expenditures across all households and for consumers only are similar in most cases because gradients in the prevalence of tobacco consumption are not steep or consistent in the countries concerned. Conversely, the share of total expenditure spent on alcoholic beverages as an average across all households in each socioeconomic group is larger in high-income households than in low-income households in all countries except Tanzania, Nicaragua, and Guatemala. However, alcoholic beverages weigh disproportionately on the expenditure of low-income households that consume alcohol in most countries.

\section{Soft drinks and snacks}

Average expenditures on soft drinks across all households in each income quintile, as a share of total expenditure, indicates that price policies would have progressive or neutral effects in most countries and regressive patterns in Guatemala and Nicaragua (figure 3C). The prevalence of consumption is lowest in lower-income quintiles, and the financial burden on consumer households consistently shows a less progressive, or even regressive, distribution. For snacks, a regressive distribution of expenditure shares averaged across all households is seen in Guatemala, Nicaragua, Panama, and Niger (figure 3D), whereas the distribution is progressive in the Asian countries and in Tanzania. However, in at least some countries, the income groups bearing the highest potential burden of price policies are those in the central part of the distribution. Because the prevalence of consumption increases with income, the burden on consumer households is more regressive, with a progressive distribution being preserved only in Tajikistan.

In summary, the burden of price increases might well be proportionately large in groups with lowest socioeconomic status, in the case of tobacco, and in groups with the highest socioeconomic status, in the case of alcohol, soft drinks, and snacks, albeit with exceptions. However, when considering only households 
that consume these product categories, the burden tends to be highest in groups with the lowest socioeconomic status.

\section{Should governments be concerned about the financial effects of price policies?}

The use of price policies by governments for the purpose of improving health has generated a large debate focused on both the benefits and the unintended consequences of such policies. The potential for price policies to have regressive financial e ffects ha s be en one of the main arguments against the use of price policies, and this argument is often used as part of opposition efforts by industry stakeholders. We have scrutinised existing data that could help governments understand the equity effects of possible price policies on tobacco, alcohol, soft drinks, and snacks. The effects of price policies are not assessed directly in our analyses because not all of the countries considered have relevant price policies in place, and where such policies are in place, the necessary data are not available or accessible. We relied instead on household expenditure data and information on consumer responsiveness to price changes to gauge the likely distribution of the effects o f p rice $\mathrm{p}$ olicies a cross $\mathrm{s}$ ocioeconomic groups.

Although it is not possible to draw a simple and generalisable conclusion from the analyses presented here, a number of important findings focused o $\mathrm{n}$ a selection of LMICs can provide helpful guidance to governments. On the whole, these findings s uggest that concerns about adverse equity effects $m$ ight $b \mathrm{e}$ outweighed, in many cases, by the expectation of health gains and by a number of pro-poor effects.

\section{Price policies affect more high-income households than low-income households}

The first finding is that price policies will affect a larger number of high-income than low-income households, and the absolute increases in expenditure involved will be largest for high-income households. This is because the prevalence of consumption of and the expenditure on alcohol, soft drinks, and snacks increase consistently with household income. This is also true for expenditure on tobacco products, although there is no clear and consistent gradient in the prevalence of tobacco use in the countries examined. An important implication of this conclusion is that the additional expenditures caused by policies that increase prices (eg, the revenues generated by taxes) come disproportionately from high-income households. Tax design can influence this effect, a nd $t$ ax $p$ olicy $m$ akers $h$ ave $t o c$ onsider potential trade-offs. F or e xample, a $v$ olumetric $t$ ax on alcohol might be more effective i $\mathrm{n} \mathrm{r}$ educing the number of units of alcohol consumed, but an ad-valorem tax would probably shift more of the financial burden onto higher-income consumers.
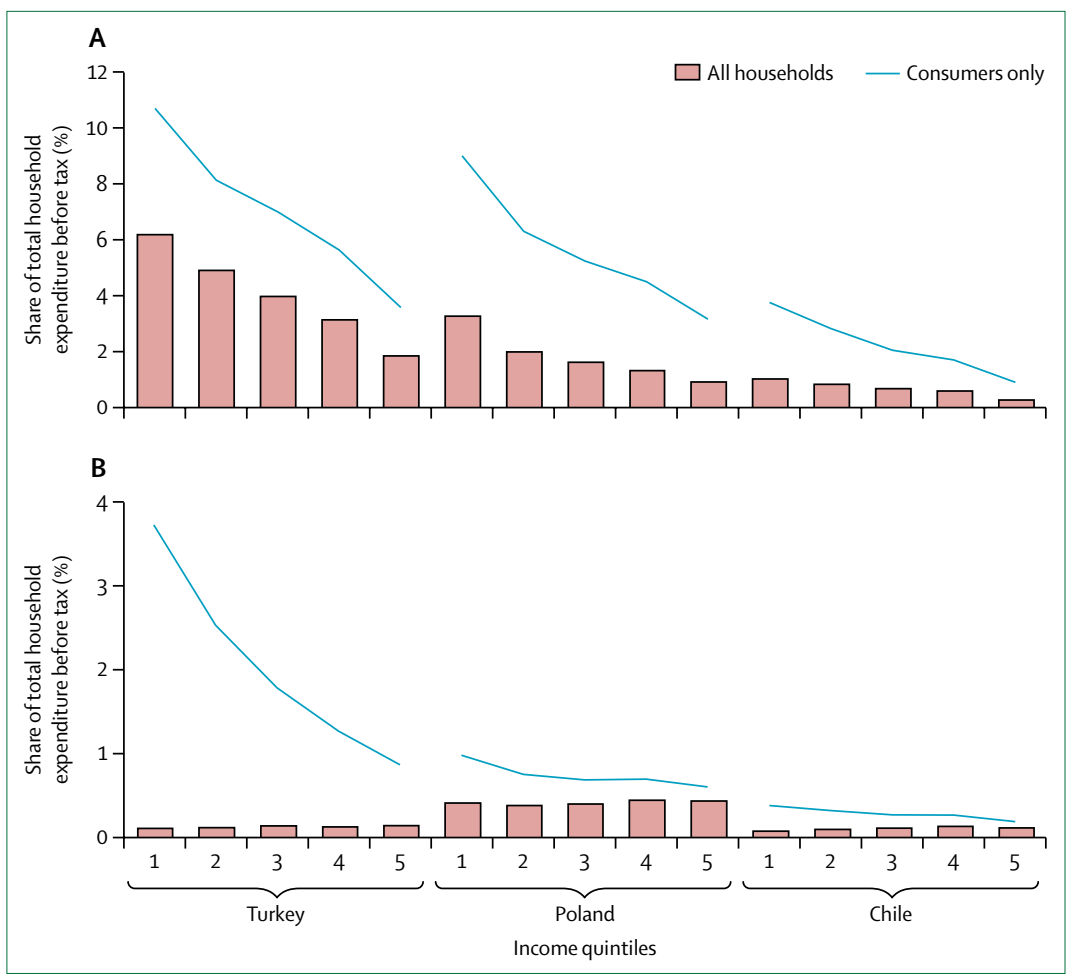

Figure 2: Tax burden of tax excises in three $O E C D$ countries by income quintile

(A) Tax excises for tobacco. (B) Tax excises for alcohol. Quintiles are ordered from 1 (bottom-income quintile) to 5 (top-wealth quintile). $\mathrm{OECD}=$ Organisation for Economic Co-operation and Development.

\section{Low-income households often (not always) bear the largest tax burden}

The second finding is about the distribution of the burden of tax policies as a proportion of total household expenditure. Low-income households bear the largest tobacco tax burden consistently across countries. The distribution of the tax burden of alcohol taxes is generally progressive, although the burden borne by just the low-income households that consume alcohol is proportionately larger than the burden borne by high-income households consuming alcohol. The potential distribution of the burden of price policies targeting soft drinks and snacks varies between countries, but again, the low-income households consuming these products tend to bear the largest financial burden.

Low-income consumers enjoy the largest health benefits Finally, the health benefits generated by price policies will be largest for low-income consumers because of their strong response to price changes, but governments must design their policies carefully to minimise unhealthy substitutions in consumption (ensuring access to healthy substitutes). At the aggregate level, higher-income groups might still accrue large health gains where there is a high prevalence of consumption in these groups.

The data for this Taskforce paper are based mostly on household expenditure surveys and are readily 

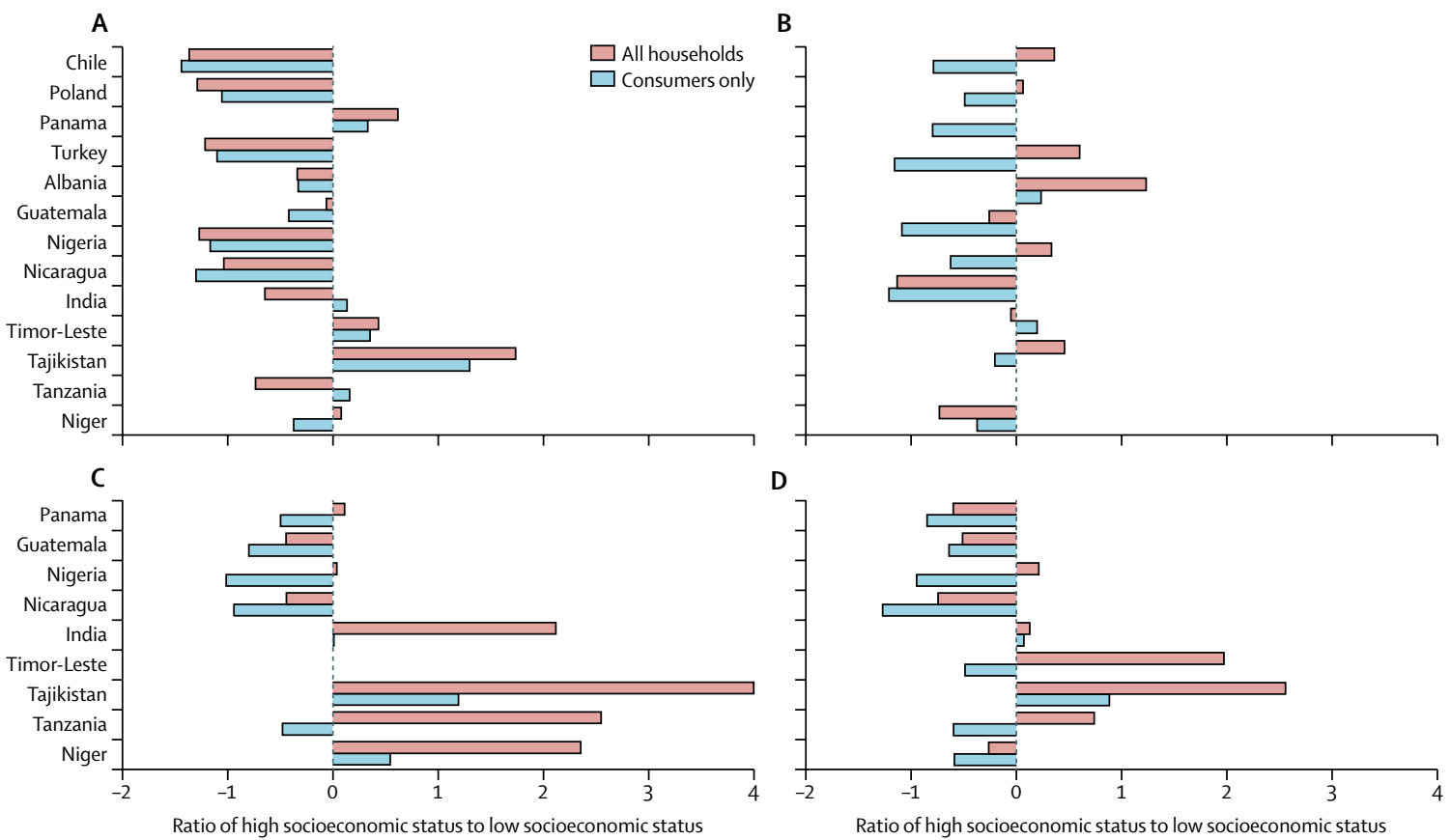

Figure 3: Socioeconomic disparities in household expenditure on four product categories as a share of total household expenditure Ratios of share of expenditure on (A) tobacco, (B) alcohol, (C) soft drinks, and (D) snacks in group with high socioeconomic status (top wealth quintile) over expenditure in the group with low socioeconomic status (bottom quintile). Ratios are calculated after logarithmic transformation of expenditure values. Ratios above zero indicate larger prevalence or expenditure in the top wealth quintile; negative ratios indicate larger prevalence or expenditure in the bottom quintile. The share of expenditure for Chile, Poland, and Turkey is calculated as a proportion of pre-tax expenditure (total household consumption exclusive of excise taxes and VAT).

available, but they have a number of limitations, typically resulting from the self-reported nature of expenditure information and from product aggregations. Additionally, the household-based nature of these datasets means that we could not identify individual-level patterns and prevalence, which are important when assessing the potential health effects of price policies, or determine the prevalence of consumption associated with increased levels of risk. The availability and reliability of household expenditure data vary greatly between countries and tend to be best in higher-income countries, but data on consumer responsiveness to price changes and likely substitutions in different socioeconomic groups are even scarcer.

\section{Health effects have financial consequences too}

Health effects, in turn, might have financial consequences for the households concerned. For instance, tobacco taxation can reduce the incidence of catastrophic health-care expenditures in low-income households (panel 2). Studies undertaken by the World Bank on tobacco taxation in Armenia ${ }^{63}$ and Chile ${ }^{64}$ have shown that taxes can increase household net incomes in the long term (by reducing out-of-pocket medical expenses and increasing earnings because of an increase in working years) and prevent catastrophic health expendi-tures and poverty in low-income populations.

\section{Whatever the measure of equity effect, price policies are never unequivocally regressive}

The direction and size of the equity effects of price policies depend to a large extent on the measures that are used to assess them and on the specific objectives of government policy. In no case are these effects unequivocally regressive. Where taxes or tax increases do generate regressive tax burdens, governments should also consider the positive financial effects linked with health improvements that are triggered by taxation as well as the size of the monetary effects involved. For example, possible taxes on sugar-sweetened beverages in the USA and in Australia were estimated to weigh more heavily on the poor, with relatively steep gradients in terms of share of tax burden on household income. However, the extra tax payments were estimated to be US\$4/low-income household per year for a US\$0.5/cent per ounce tax in the USA, and up to AU\$3.7 for a AU\$0.2/L tax in Australia (averages across all households in each income group). ${ }^{65,66}$ Of course, no amount of money, however small, is trivial for low-income households, especially in low-income countries, but governments must carefully consider whether the amounts involved are a barrier to the implementation of a potentially beneficial health policy, from which people from lower-income groups are likely to benefit disproportionately.

Another reason for interpretting the regressive effects described here and elsewhere cautiously is that at least the 
most common type of price policy (ie, taxation) generates substantial amounts of government revenues that can be used to mitigate or even offset any unfair distribution of tax burden. Whether or not tax revenues are earmarked (and several important examples of earmarking exist; eg, in Thailand and Philippines [appendix]), the revenues generated will contribute to the growing tax revenue pool that is typically used by governments to deliver public services, of which low-income people might benefit disproportionately.

In China and in India, a 50\% increase in tobacco prices would lead to larger decreases in expenditure on tobacco-related diseases, as a share of income, in the bottom-income quintiles than in the top-income quintile, providing financial risk protection to people with the lowest incomes. ${ }^{23}$ Jan and colleagues, ${ }^{67}$ in the third paper of this Taskforce, provide further examples of how governments can use revenues for risk protection. Finally, what governments are, or should be, mostly concerned about is the regressive or progressive nature of their tax system as a whole, not individual tax measures. When Denmark introduced an innovative tax on saturated fat in 2011, it did this as part of a broader tax reform that altered the progressivity of its income tax. ${ }^{68}$

Our analysis provides some clear evidence on numerous effects that countries can expect from price policies on the four aggregates of products. A final lesson from the analyses is that a detailed assessment is needed in each setting and for each policy because important dimensions of effects cannot be generalised, and uniform patterns cannot always be identified. The social dimensions of consumer behaviours vary between and within countries. Claims that are not based on a detailed analysis of country-specific data are bound to be simplistic and most likely misguided.

\section{Contributors}

$\mathrm{FS}, \mathrm{AB}, \mathrm{MS}$, and RN conceived the study. AJM obtained the data and analysed the LSMS data. AT obtained and analysed data for Chile, Poland, and Turkey. SV obtained and analysed data for India. BMP drafted panel 1 , NS drafted panel 2, CV drafted the focus on earmarking. All authors contributed to the interpretation of findings and to the writing of this Taskforce paper.

Declaration of interests

NS reports a grant from International Development Research Centre, during the conduct of the study. RN reports grants from Bloomberg Philanthropies and from Cancer Research UK, outside the submitted work. The opinions expressed and arguments used in this paper are solely those of the authors and do not necessarily reflect the official views of the OECD or its member countries.

\section{Acknowledgments}

We thank Robert Beaglehole, co-ordinator of The Lancet Taskforce on NCDs and economics. A grant from the International Development Research Centre funded collaborative travel for several authors of this Taskforce paper.

\section{References}

1 UN. Political declaration of the high-level meeting of the general assembly on the prevention and control of non-communicable diseases. New York, NY: United Nations, 2011.

2 Di Cesare $\mathrm{M}$, Khang $\mathrm{YH}$, Asaria P. Inequalities in non-communicable diseases and effective responses. Lancet 2013; 381: 585-97.
3 Asaria P, Chisholm D, Mathers C, Ezzati M, Beaglehole R. Chronic disease prevention: health effects and financial costs of strategies to reduce salt intake and control tobacco use. Lancet 2007; 370: 2044-53.

4 Abegunde DO, Mathers CD, Adam T, Ortegon M, Strong K. The burden and costs of chronic diseases in low-income and middle-income countries. Lancet 2007; 370: 1929-38.

5 Sassi F. Obesity and the economics of prevention: fit not fat. Paris: OECD Publishing, 2010.

6 Sassi F. Tackling harmful alcohol use: economics and public health policy. Paris: OECD Publishing, 2015

7 WHO. WHO framework convention on tobacco control. Geneva: World Health Organization, 2003.

8 WHO. Global strategy to reduce the harmful use of alcohol. Geneva: World Health Organization, 2010

9 OECD. Obesity update 2012. Paris: OECD Publishing, 2012.

10 OECD. Obesity update 2014. Paris: OECD Publishing, 2014.

11 Powell LM, Chriqui JF, Khan T, Wada R, Chaloupka FJ. Assessing the potential effectiveness of food and beverage taxes and subsidies for improving public health: a systematic review of prices, demand and body weight outcomes. Obes Rev 2013; 14: $110-28$.

12 Stockwell T, Zhao J, Martin G, et al. Minimum alcohol prices and outlet densities in British Columbia, Canada: estimated impacts on alcohol-attributable hospital admissions. Am J Public Health 2013; 103: 2014-20.

13 UN. Report of the third International Conference on Financing for Development, Addis Ababa, 13-16 July, 2015. New York, NY: United Nations, 2015.

14 Stenberg K, Elovainio R, Chisholm D, et al. Responding to the challenge of resource mobilization- mechanisms for raising additional domestic resources for health. World Health Report 2010. Background Paper, 13. Geneva: World Health Organization, 2010.

15 Sassi F, Hurst J. The prevention of lifestyle-related chronic diseases: an economic framework. OECD Health working paper number 32. Paris: OECD Publishing, 2008.

16 Suhrcke M, Nugent RA, Stuckler A, Rocco L. Chronic disease: an economic perspective. London: Oxford Health Alliance, 2006.

17 Cawley J, Frisvold D. The incidence of taxes on sugar-sweetened beverages: the case of Berkeley, California. NBER working paper number 21465. Cambridge, MA: National Bureau of Economic Research, 2015.

18 Remler DK. Poor smokers, poor quitters, and cigarette tax regressivity. Am J Public Health 2004; 94: 225-29.

19 Sreeramareddy CT, Pradhan PMS. Prevalence and social determinants of smoking in 15 countries from north Africa, central and western Asia, Latin America and Caribbean: secondary data analyses of demographic and health surveys. PLoS One 2015; 10: e0130104.

20 Devaux M, Sassi F. Alcohol consumption and harmful drinking: trends and social disparities across OECD countries. OECD Health working paper number 79. Paris: OECD Publishing, 2015.

21 Chaloupka FJ, Yurekli A, Fong GT. Tobacco taxes as a tobacco control strategy. Tob Control 2012; 21: 172-80.

22 Levy DT, Chaloupka FJ, Gitchell J. The effects of tobacco control policies on smoking rates: a tobacco control scorecard. J Public Health Manag Pract 2004; 10: 338-53.

23 Verguet S, Gauvreau CL, Mishra S, et al. The consequences of tobacco tax on household health and finances in rich and poor smokers in China: an extended cost-effectiveness analysis. Lancet Glob Health 2015; 3: e206-16.

24 Nargis N, Ruthbah UH, Hussain AK, Fong GT, Huq I, Ashiquzzaman SM. The price sensitivity of cigarette consumption in Bangladesh: evidence from the International Tobacco Control (ITC) Bangladesh Wave 1 (2009) and Wave 2 (2010) Surveys. Tob Control 2014; 23 (suppl 1): i39-47.

25 Huang J, Zheng R, Chaloupka FJ, Fong GT, Jiang Y. Differential responsiveness to cigarette price by education and income among adult urban Chinese smokers: findings from the ITC China Survey. Tob Control 2015; 24: iii76-82.

26 Wagenaar AC, Salois MJ, Komro KA. Effects of beverage alcohol price and tax levels on drinking: a meta-analysis of 1003 estimates from 112 studies. Addiction 2009; 104: 179-90. 
27 Fogarty J. The demand for beer, wine and spirits: insights from a meta-analysis approach. AAWE working paper number 31. New York, NY: American Association of Wine Economists, 2008

28 Gallet CA. The demand for alcohol: a meta-analysis of elasticities. Aus J Agric Res Econ 2007; 51: 121-35.

29 Nelson JP. Meta-analysis of alcohol price and income elasticitieswith corrections for publication bias. Health Econ Rev 2013; 3: 17.

30 Sornpaisarn B. Shield K, Cohen J et al. Elasticity of alcohol consumption, alcohol-related harms, and drinking initiation in low-and middle-income countries: a systematic review and meta-analysis. Int J Drug Alcohol Res 2013; 2: 1-14.

31 Ayyagari P, Deb P, Fletcher J, Gallo W, Sindelar JL Understanding heterogeneity in price elasticities in the demand for alcohol for older individuals. Health Econ 2013; 22: 89-105.

32 The Alcohol and Public Policy Group. Alcohol, no ordinary commodity: research and public policy. Oxford: Oxford University Press, 2010.

33 Holmes J, Meng Y, Meier PS, et al. Effects of minimum unit pricing for alcohol on different income and socioeconomic groups: a modelling study. Lancet 2014; 383: 1655-64.

34 Hawkes C. Financial incentives and disincentives to encourage healthy eating. London: Which?, 2009.

35 Eyles H, Ni Mhurchu C, Nghiem N, Blakely T. Food pricing strategies, population diets, and non-communicable disease: a systematic review of simulation studies. PLoS Med 2012; 9: e1001353.

36 Thow AM, Jan S, Leeder S, Swinburn B. The effect of fiscal policy on diet, obesity and chronic disease: a systematic review. Bull World Health Organ 2010; 88: 609-14.

37 Shemilt I, Hollands GJ, Marteau TM, et al. Economic instruments for population diet and physical activity behaviour change: a systematic scoping review. PLoS One 2013; 8: e75070.

38 Shemilt I, Marteau TM, Smith RD, Ogilvie D. Use and cumulation of evidence from modelling studies to inform policy on food taxes and subsidies: biting off more than we can chew? BMC Public Health 2015; 15: 297.

39 Green R, Cornelsen L, Dangour AD, et al. The effect of rising food prices on food consumption: systematic review with meta-regression. BMJ 2013; 346: f3703.

40 Cornelsen L, Green R, Turner R, et al. What happens to patterns of food consumption when food prices change? Evidence from a systematic review and meta-analysis of food price elasticities globally. Health Econ 2015: 24: 1548-59.

41 Nakhimovsky SS, Feigl AB, Avila C, O’Sullivan G, Macgregor-Skinner E, Spranca M. Taxes on sugar-sweetened beverages to reduce overweight and obesity in middle-income countries: a systematic review. PLoS One 2016; 11: e0163358.

42 Backholer K, Sarink D, Beauchamp A, et al. The impact of a tax on sugar-sweetened beverages according to socio-economic position: a systematic review of the evidence. Public Health Nutr 2016; 19: $3070-84$.

43 Colchero MA, Salgado JC, Unar-Munguía M, Molina M, Ng S, Rivera-Dommarco JA. Changes in prices after an excise tax to sweetened sugar beverages was implemented in Mexico: evidence from urban areas. PLoS One 2015; 10: e0144408.

44 Colchero MA, Popkin BM, Rivera JA, Ng SW. Beverage purchases from stores in Mexico under the excise tax on sugar sweetened beverages: observational study. BMJ 2016; 352: h6704.

45 Colchero MA, Rivera-Dommarco J, Popkin BM, Ng SW. In Mexico, evidence of sustained consumer response two years after implementing a sugar-sweetened beverage tax. Health Affairs 2017; 36: 564-71.

46 Colchero M, Guerrero-López CM, Molina M, Rivera JA. Beverages sales in Mexico before and after implementation of a sugar sweetened beverage tax. PLoS One 2016; 11: e0163463.

47 Cecchini M, Sassi F, Lauer JA, Lee YY, Guajardo-Barron V, Chisholm D. Tackling of unhealthy diets, physical inactivity, and obesity: health effects and cost-effectiveness. Lancet 2010; 376: $1775-84$.
48 Institute for Health Metrics and Evaluation. Global burden of disease. http://www.healthdata.org/gbd (accessed Sept 1, 2013).

49 Salti N, Chaaban J, Naamani N. The economics of tobacco in Lebanon: an estimation of the social costs of tobacco consumption. Subst Use Misuse 2014; 49: 735-42.

50 Chakrani H. Smoking: 2379 cigarettes per capita in Lebanon. Al-Akhbar English, June 10, 2013. http://english.al-akhbar.com/ node/16064 (accessed May 29, 2015).

51 Salti N, Chaaban J, Nakkash R, Alaouie H. The effect of tobacco taxation on tobacco consumption and public revenues in Lebanon. Tob Control 2015; 24: 77-81.

52 The Lebanese Central Administration of Statistics. National living conditions of households survey 2004. http://www.cas.gov.lb/ index.php/all-publications-en\#households-living-conditionssurvey-2004 (accessed June 21, 2015)

53 National Customs Authority of Lebanon. Data on imports of tobacco 1997-2011. Beirut, Lebanon: National Customs Authority, 2012.

54 Mahdi B, 2014, presentation on "Simulating an increase in tobacco taxes," Ministry of Public Health, the Framework Convention Alliance and Green Hand conference on tobacco taxation in Lebanon, October 29, 2014, Beirut, Lebanon.

55 Deaton A, Muellbauer J. An almost ideal demand system. Am Econ Rev 1980; 70: 312-26.

56 Chaloupka FJ, Grossman M. Price, tobacco control policies and youth smoking. NBER working paper number 5740. Cambridge, MA: National Bureau of Economic Research, 1996.

57 Ministry of Public Health of Lebanon. Statistical bulletin, 2011. http://www.moph.gov.lb/Publications/Documents/Statistical\%20 Bulletin\%202011.pdf (accessed July 17, 2015).

58 Salti N, Brouwer E, Verguet S. The health, financial and distributional consequences of increases in the tobacco excise tax among smokers in Lebanon. Soc Sci Med 2016; 170: 161-69.

59 Verguet S, Laxminarayan RL, Jamison DT. Universal public finance of tuberculosis treatment in India: an extended cost-effectiveness analysis. Health Econ 2015; 24: 318-32.

60 OECD/Korea Institute of Public Finance. The distributional effects of consumption taxes in OECD countries. OECD tax policy studies number 22. Paris: OECD Publishing, 2014.

61 Beaglehole R, Ebrahim S, Reddy S, et al. Prevention of chronic diseases: a call to action. Lancet 2007; 370: 2152-57.

62 Leicester A. Alcohol pricing and taxation policies. IFS Briefing Note BN124. London: Institute for Fiscal Studies, 2011.

63 Postolovska I, Lavado RF, Tarr G, Verguet S. Estimating the distributional impact of increasing taxes on tobacco products in armenia : results from an extended cost-effectiveness analysis. Washington, DC: World Bank, 2017.

64 Fuchs A, Meneses F. Are tobacco taxes really regressive? Evidence from Chile. Washington, DC: World Bank, 2017.

65 Zhen C, Finkelstein EA, Nonnemaker J, Karns S, Todd JE. Predicting the effects of sugar-sweetened beverage taxes on food and beverage demand in a large demand system. Am J Agr Econ 2013; 96: 1-25

66 Sharma A, Hauck K, Hollingsworth B, Siciliani L. The effects of taxing sugar-sweetened beverages across different income groups. Health Econ 2014; 23: 1159-84.

67 Jan S, Laba T-L, Essue B, et al. Action to address the household economic burden of non-communicable diseases. Lancet 2018; published online April 4. http://dx.doi.org/10.1016/S01406736(18)30323-4

68 Danish Ministry of Taxation. Danish tax reform 2010. Copenhagen: Danish Ministry of taxation, 2009. 